Article

\title{
The Marine Catenovulum agarivorans MNH15 and Dextranase: Removing Dental Plaque
}

\author{
Xiaohua Lai ${ }^{1,2, \dagger}$, Xin Liu ${ }^{1,2, \dagger}$, Xueqin Liu ${ }^{1,2}$, Tian Deng ${ }^{1,2}$, Yanli Feng ${ }^{1,2}$, Xiaopeng Tian ${ }^{1,2}$, \\ Mingsheng Lyu 1,2,3,*(D) and Shujun Wang 1,2,3,* \\ 1 Jiangsu Key Laboratory of Marine Bioresources and Environment/Jiangsu Key Laboratory of Marine \\ Biotechnology, Jiangsu Ocean University, Lianyungang 222005, China; huaxiaolai10@163.com (X.L.); \\ liuxin1490@163.com (X.L.); xueqinliu123@163.com (X.L.); dengtian729@163.com (T.D.); \\ ylfeng0@163.com (Y.F.); txpxiaopeng@163.com (X.T.) \\ 2 Co-Innovation Center of Jiangsu Marine Bio-industry Technology, Jiangsu Ocean University, \\ Lianyungang 222005, China \\ 3 Collaborative Innovation Center of Modern Biological Manufacturing, Anhui University, Hefei 230039, China \\ * Correspondence: mingshenglu@hotmail.com (M.L.); shujunwang86@163.com (S.W.) \\ + These authors are contributed equally to this work.
}

Received: 29 August 2019; Accepted: 16 October 2019; Published: 18 October 2019

\begin{abstract}
Dextranase, a hydrolase that specifically hydrolyzes $\alpha-1,6$-glucosidic bonds, has been used in the pharmaceutical, food, and biotechnology industries. In this study, the strain of Catenovulum agarivorans MNH15 was screened from marine samples. When the temperature, initial $\mathrm{pH}, \mathrm{NaCl}$ concentration, and inducer concentration were $30{ }^{\circ} \mathrm{C}, 8.0,5 \mathrm{~g} / \mathrm{L}$, and $8 \mathrm{~g} / \mathrm{L}$, respectively, it yielded more dextranase. The molecular weight of the dextranase was approximately $110 \mathrm{kDa}$. The maximum enzyme activity was achieved at $40{ }^{\circ} \mathrm{C}$ and a $\mathrm{pH}$ of 8.0 . The enzyme was stable at $30^{\circ} \mathrm{C}$ and a $\mathrm{pH}$ of 5-9. The metal ion $\mathrm{Sr}^{2+}$ enhanced its activity, whereas $\mathrm{NH}^{4+}, \mathrm{Co}^{2+}, \mathrm{Cu}^{2+}$, and $\mathrm{Li}^{+}$had the opposite effect. The dextranase effectively inhibited the formation of biofilm by Streptococcus mutans. Moreover, sodium fluoride, xylitol, and sodium benzoate, all used in dental care products, had no significant effect on dextranase activity. In addition, high-performance liquid chromatography (HPLC) showed that dextran was mainly hydrolyzed to glucose, maltose, and maltoheptaose. The results indicated that dextranase has high application potential in dental products such as toothpaste and mouthwash.
\end{abstract}

Keywords: Catenovulum agarivorans; dextranase; dental plaque; oligo-saccharides

\section{Introduction}

Dextran is a water-soluble polysaccharide linked by $\alpha$-1,6-glucosidic bonds, which can be synthesized by bacteria such as Leuconostoc mesenteroides, Streptococcus, and Rhizopus [1-3]. Water-soluble exopolysaccharides of dextran mainly play a role in plaque formation [4,5]. In addition, microbes use sucrose to produce large amounts of dextran, which has led to a decrease in the yield and quality of sucrose in the sugar industry [6-9]. So far, several methods have been used to control the formation of dextran, such as antibacterial agents, mechanical removal, and biological enzymes [10,11]. It has been proven that dextranase can hydrolase dextran safety and effectively.

Dextranase ( $\alpha$-1,6-d-glucan-6-glucanohydrolase, E.C.3.2.1.11), an inducible enzyme, is a hydrolase that catalyzes the hydrolysis of $\alpha-1,6$-glucosidic bonds in dextran [12-14]. Bio-enzymatic hydrolysis of dextran is not only used in the preparation of dextran and its derivatives, but also plays an important role in the production of beverages and syrups in the food industry [15]. In sugar industries, dextranase can hydrolyze dextran in sugar juice, which can reduce its viscosity and increase the yield of sucrose $[8,9,16]$. In medicine, dextranase can degrade the high molecular weight of dextran into a 
low molecular weight. The specific molecular weight of dextran has an antithrombotic effect and can be used as a blood substitute in emergencies $[17,18]$. Currently, dextranase produced by fungi is mainly added to oral care products such as toothpaste and mouthwash to treat oral biofilm [19-23]. Larsson et al. reported on the catalytic reaction of Penicillium dextranase, the crystal structure of the enzyme, and the product complex [24]. The optimum temperature of dextranase produced by fungi was higher than $50^{\circ} \mathrm{C}$ and unstable under alkaline conditions [22]. It has also been reported that dextranase is mainly produced by terrestrial bacteria [25-27]. Cold-adapted enzymes from the ocean can serve as a source of new marine medicines $[28,29]$ and have enormous biotechnology potential in dairy products, sugar, detergents, and bioremediation [30,31].

Dextranase produced by marine bacteria has the characteristics of alkali resistance, salt tolerance, and high catalytic activity at moderate temperatures [32-34]. Majeed et al. reported that alkaline dextranase may play an important role in the treatment of oral plaque because alkaline mouthwash products are more protective than enamel against acidic products [35]. Therefore, it is desirable to explore more marine bacterial dextranases. Dextranase with better characteristics is more suitable for oral care products and is still widely in demand for preventing dental caries.

In this study, we isolated marine bacteria producing dextranase; identified their physiological and biochemical characteristics and molecular biology; and then studied bacterial growth characteristics, dextranase properties, and the effect of plaque removal. All the results indicated that the characteristics of dextranase are excellent and worth studying to identify its further application.

\section{Results}

\subsection{Screened Marine Strains Producing Dextranase}

Five strains of dextran-producing strains were selected from blue dextran plates containing different marine samples. After comparing their hydrolysis abilities, the strain with highest enzyme-producing ability, MNH15 (Figure 1a), was selected (Table 1).
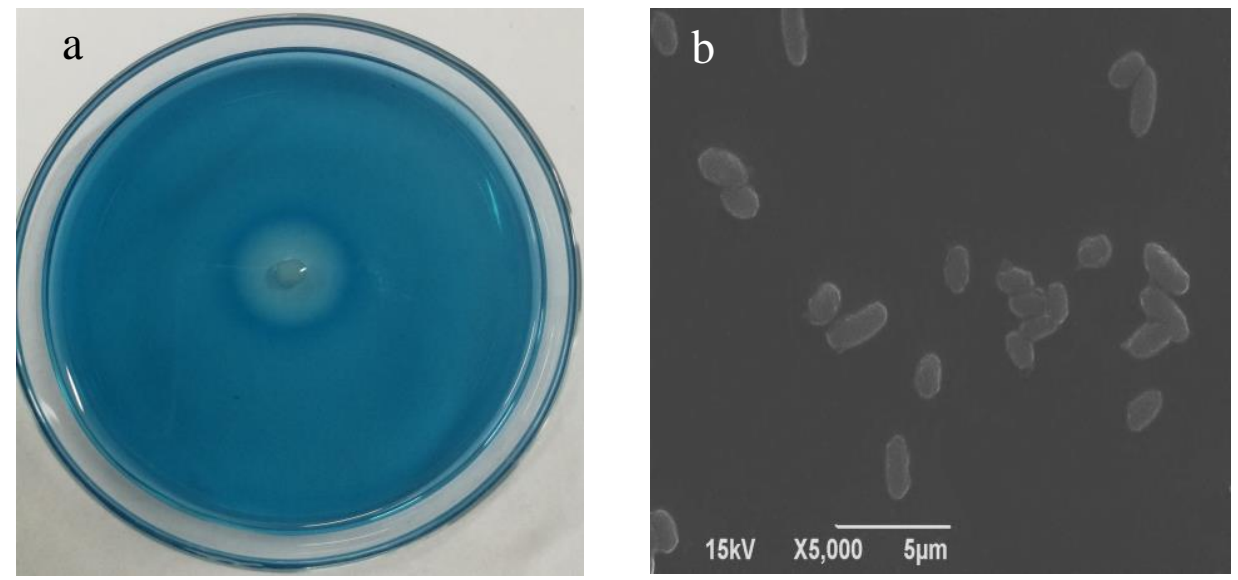

Figure 1. Transparent zone formed by the strain MNH15 on the plate containing blue dextran (a) and scanning electron micrograph (b).

Table 1. Strains with different hydrolysis abilities.

\begin{tabular}{cccc}
\hline Isolates & Colony Diameter $(\mathbf{d}, \mathbf{m m})$ & Halo Diameter $(\mathbf{D}, \mathbf{m m})$ & ${\text { Hydrolysis Ability }(\mathbf{D} / \mathbf{d})^{\mathbf{2}}}^{\text {(n) }}$ \\
\hline MNH10 & 3.00 & 5.00 & 2.78 \\
MNH8 & 2.00 & 11.00 & 30.25 \\
MNH15 & 2.00 & 13.00 & 42.25 \\
BN2 & 4.00 & 9.00 & 5.06 \\
MN7 & 3.00 & 6.00 & 4.00 \\
\hline
\end{tabular}




\subsection{Identification of Strain MNH15}

The morphological and biochemical characteristics of strain MNH15 are shown in Table 2. The strain was Gram-negative, aerobic, short rod-shaped (Figure $1 \mathrm{~b}$ ), grown at $37^{\circ} \mathrm{C}$, and did not grow at $4{ }^{\circ} \mathrm{C}$. Using genomic DNA from strain MNH15 as a template, a $16 \mathrm{~S}$ universal primer was used for polymerase chain reaction, and the amplified fragment was about $1.5 \mathrm{~kb}$ (Figure $2 \mathrm{a}$ ). After the PCR product was recovered, it was ligated to the pMD19-T cloning vector and transferred to E.-coli-competent cells, after which the positive clones were selected and sequenced to obtain a 1595 bp sequence. The $16 \mathrm{~S}$ rDNA gene sequence was retrieved by GenBank and compared with its $16 \mathrm{~S}$ rDNA sequence, and the phylogenetic tree was calculated using MEGA software ver. 5.0 and Clustal ver. 1.83. The phylogenetic tree indicated that strain MNH15 belonged to the genus Catenovulum (Figure 2b). On the basis of the morphological and biochemical characteristics combined with gene sequence analysis, the selected strain was recorded as Catenovulum agarivorans MNH15.

The optimum growth temperature was $35^{\circ} \mathrm{C}$ (Figure 3a). The strain MNH15 could grow at a wide $\mathrm{pH}$ range, but a $\mathrm{pH}$ of 8.0 was optimum (Figure $3 \mathrm{~b}$ ). The strain was grown in a medium containing $1 \%-7 \% \mathrm{NaCl}$ at an optimum concentration of $2 \%$ and did not grow without $\mathrm{NaCl}$ (Figure 3c). The logarithmic growth phase of the strain was $3-6 \mathrm{~h}$, and the dextranase activity increased gradually between $24 \mathrm{~h}$ and $48 \mathrm{~h}$ (Figure 3d).

Table 2. Morphological, physiological, and biochemical characteristics of strain MNH15.

\begin{tabular}{cccc}
\hline Item & Result & Item & Result \\
\hline Colony color & Milky & Sucrose & + \\
Shape & Oval & Cellobiose & - \\
Gram stain & - & Hydrogen sulfide & - \\
Spore & - & Mannitol & - \\
Motility & + & Glucose & + \\
$4^{\circ} \mathrm{C}$ & & Arabic candy & - \\
$37^{\circ} \mathrm{C}$ & + & Raffinose & - \\
$\mathrm{NaCl}$ range for growth $(w / v, \%)$ & $0.5-7$ & Trehalose & + \\
Arginine decarboxylase & - & Urea & - \\
Lysine decarboxylase & - & Phosphate & + \\
Ornithine decarboxylase & - & Galactose & + \\
Xylose & - & Red fresh & + \\
Lactose & - & Ribose & + \\
Maltose & + & Arab alcohol & + \\
\hline
\end{tabular}

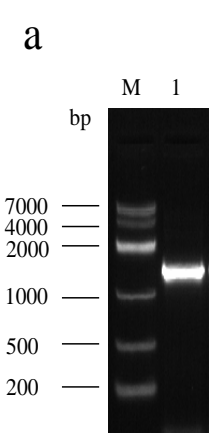

$\mathrm{b}$

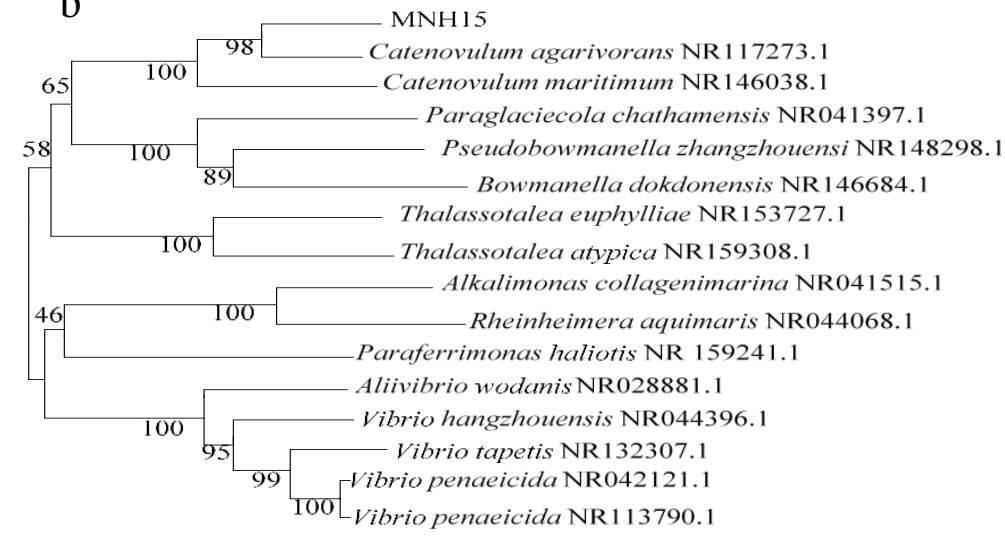

$\longdiv { 0 . 0 1 0 0 }$

Figure 2. Agarose electrophoresis profiles of $16 \mathrm{~S}$ rDNA PCR products M: DNA marker (Sangon, China); 1: strain MNH1516S rDNA PCR amplification product (a). Phylogenetic tree based on 16S rDNA gene sequences $(\mathbf{b})$. 

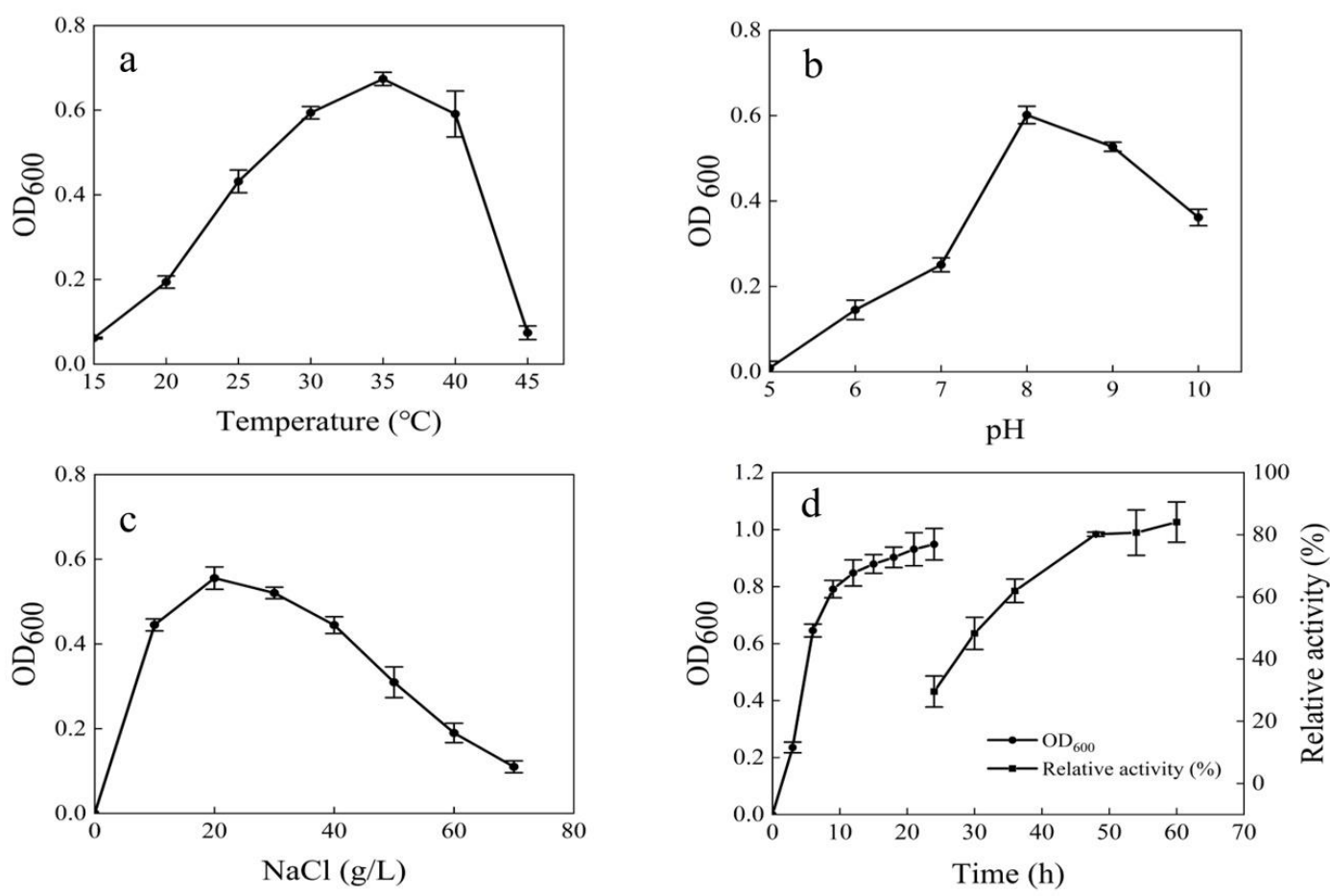

Figure 3. The effects of temperature (a), $\mathrm{pH}(\mathbf{b})$, and $\mathrm{NaCl}$ concentration (c) on the growth of the strain MNH15 and dextranase producing time (d).

\subsection{Dextranase-Producing Conditions}

\subsubsection{Effects of Carbon and Nitrogen Source on Dextranase Production}

The effects of different carbon sources and nitrogen sources on the dextranase-producing strain MNH15 are shown in Figure 4. Barley flour was the best carbon source for the production of dextranase. Soluble starch and maltose had a slight effect on the strain producing dextranase. However, potato starch, tapioca starch, lactose, corn starch, glucose, rice bran, bran, sucrose, and dextrin could promote the production of dextranase (Figure 4a). Casein was the best nitrogen source (Figure $4 b$ ), followed by soybean meal and peanut meal, whereas casein was costly and unsuitable for large-scale fermentation. Therefore, soybean meal was selected as the nitrogen source.
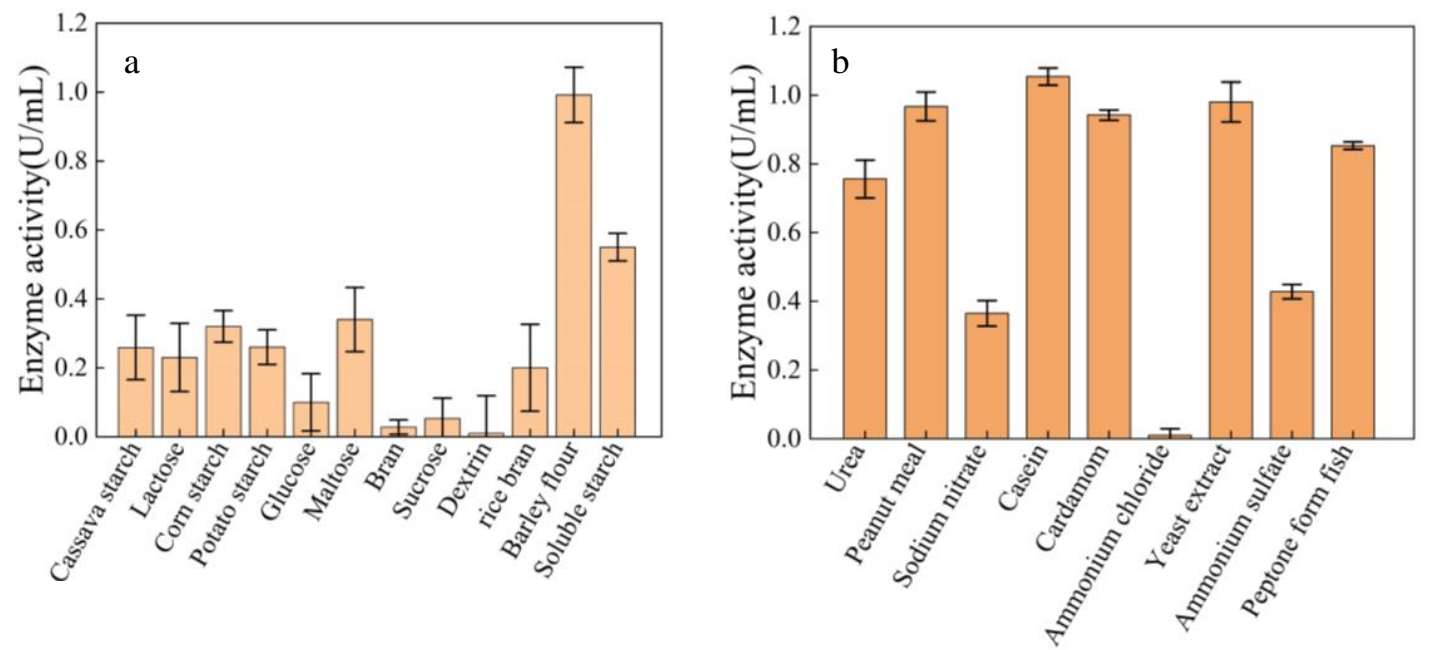

Figure 4. Effect of carbon source (a) and nitrogen source (b) on dextranase-producing by strain MNH15. 


\subsubsection{Effects of Temperature, $\mathrm{pH}$, and $\mathrm{NaCl}$ Concentration on Dextranase Production}

The optimal temperature for producing dextranase from strain $\mathrm{MNH} 15$ was $30^{\circ} \mathrm{C}$. When the temperature was higher or lower, the dextranase-producing capacity changed sharply (Figure 5a). The initial $\mathrm{pH}$ of the medium was adjusted to the range of 5.0-10.0, and the dextranase activity was measured after $48 \mathrm{~h}$ of fermentation. At a $\mathrm{pH}$ of 8.0, the strain was most beneficial to dextranase production (Figure $5 \mathrm{~b}$ ). When the $\mathrm{NaCl}$ concentration was $5 \mathrm{~g} / \mathrm{L}$, the dextranase-producing capacity reached its peak (Figure $5 \mathrm{c}$ ). Moreover, the $\mathrm{NaCl}$ concentration had a significant effect on the growth and the enzyme-producing capacity.
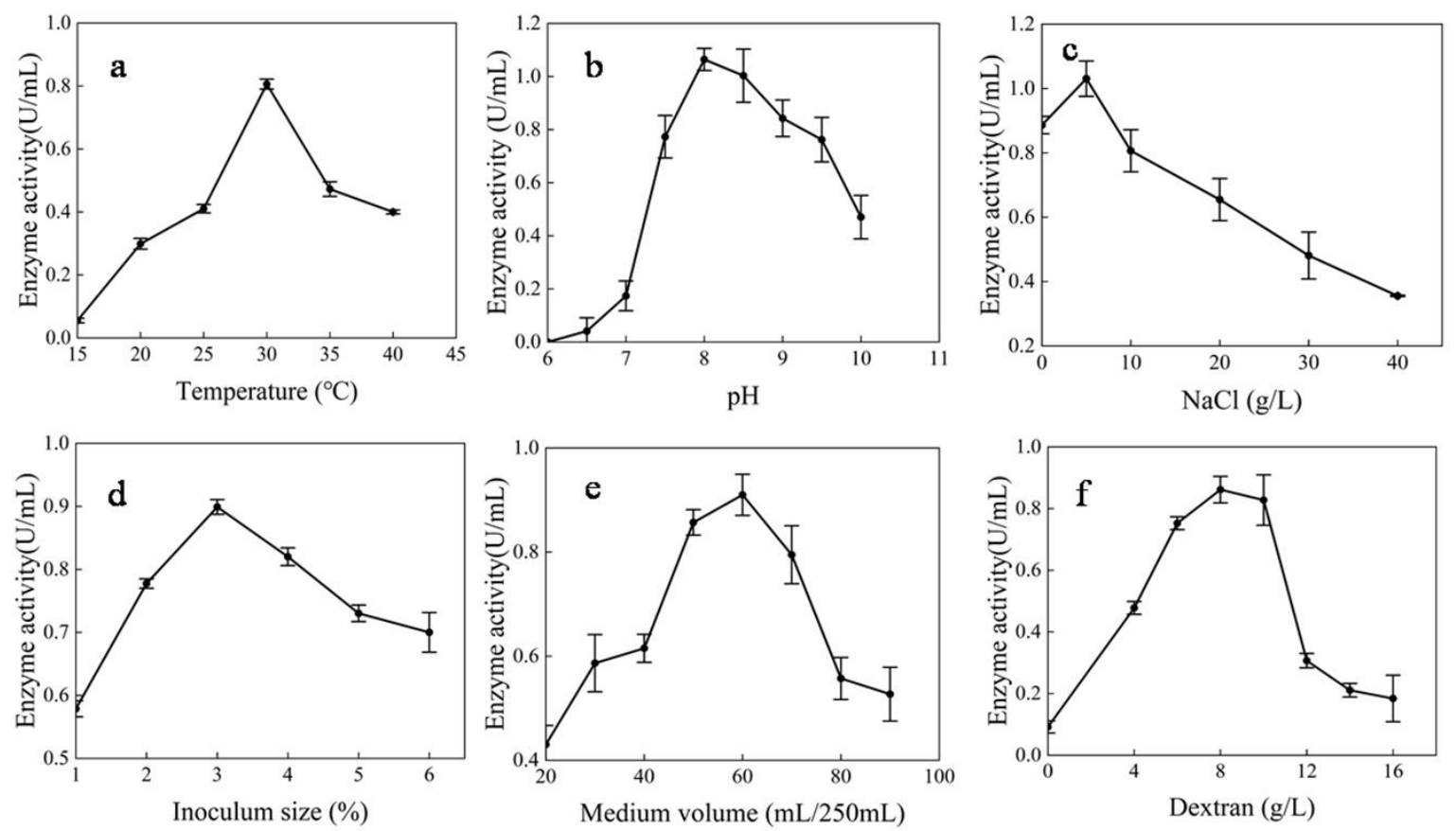

Figure 5. Effects of temperature (a), initial $\mathrm{pH}(\mathbf{b}), \mathrm{NaCl}$ concentration (c), inoculum size (d), medium volume (e), and inducer concentration (f) on dextranase production. For each effect on dextranase activity, the values are shown as percentages of the maximum activities, which were taken as $100 \%$.

\subsubsection{Effects of Inoculum Size, Aeration, and Inducer Concentration on Dextranase Production}

As Figure $5 \mathrm{~d}$ shows, the inoculum size had an important effect on dextranase production. The optimal inoculum amount was 3\%. When $60 \mathrm{~mL}$ of medium was added to a $250 \mathrm{~mL}$ Erlenmeyer flask, the amount of aeration was most favorable for dextranase production (Figure 5e). The results clearly showed that the dextranase production needed an inducer (Figure 5f). A dextran T20 concentration of $8 \mathrm{~g} / \mathrm{L}$ was the most beneficial to dextranase production.

\subsection{Enzymatic Characterization}

The dextranase was subjected to sodium dodecyl sulfate (SDS)-polyacrylamide gel electrophoresis (PAGE). The band in the Coomassie blue-stained gel was consistent with the position of the transparent band in the blue dextran gel (Figure 6). This result showed that the molecular weight of the dextranase was between $100 \mathrm{kDa}$ and $130 \mathrm{kDa}$ (around $110 \mathrm{kDa}$ ). 


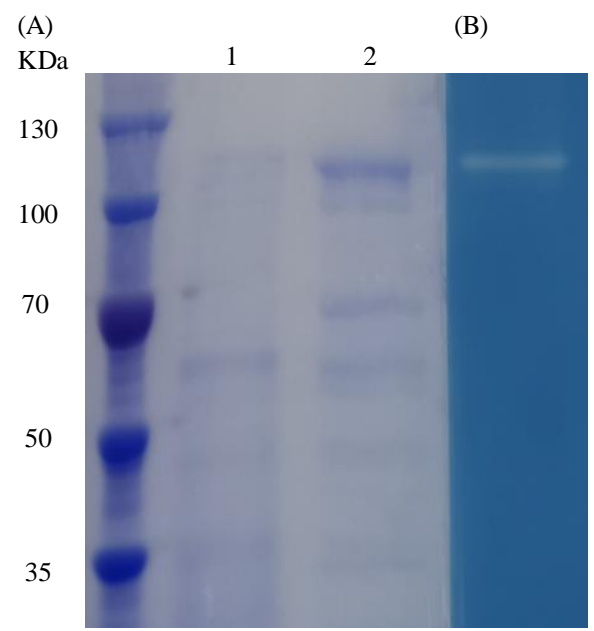

Figure 6. (A) Coomassie brilliant blue-stained 8\% sodium dodecyl sulfate (SDS)-polyacrylamide gel electrophoresis (PAGE) gel showing the size of the dextranase. M Molecular weight standard (Sangon China, C610011); L1 crude fermentation broth of Catenovulum agarivorans. MNH15; L2 the crude fermentation broth of strain MNH15 was concentrated with a $30 \mathrm{~K}$ ultrafiltration tube (Millipore). (B) Transparent strip showing dextranase activity on an $8 \%$ native PAGE gel containing 3\% ( $w / v)$ blue dextran. The numbers on the left indicate the size of the markers.

\subsubsection{Effects of Temperature and $\mathrm{pH}$ on Dextranase Activity and Stability}

The effect of temperature on dextranase activity is shown in Figure 7a. Dextranase activity was very sensitive to temperature change, with the optimum temperature being $40^{\circ} \mathrm{C}$. Dextranase activity peaked at a $\mathrm{pH}$ of 8.0, as shown in Figure $7 \mathrm{~b}$. The dextranase maintained a high activity level in the $\mathrm{pH}$ range of 6.0-8.0. In addition, the dextranase was very stable in the $\mathrm{pH}$ range of $4.0-9.0$ at $25^{\circ} \mathrm{C}$ (Figure $7 \mathrm{~b}$ ). The thermal stability of dextranase showed that the residual activity level stayed at almost $100 \%$ following storage for $5 \mathrm{~h}$ at $30{ }^{\circ} \mathrm{C}(\mathrm{pH} 8.0)$, and nearly $50 \%$ of the enzyme activity was lost following storage at $45^{\circ} \mathrm{C}$ for $5 \mathrm{~h}$ (Figure $7 \mathrm{c}$ ).
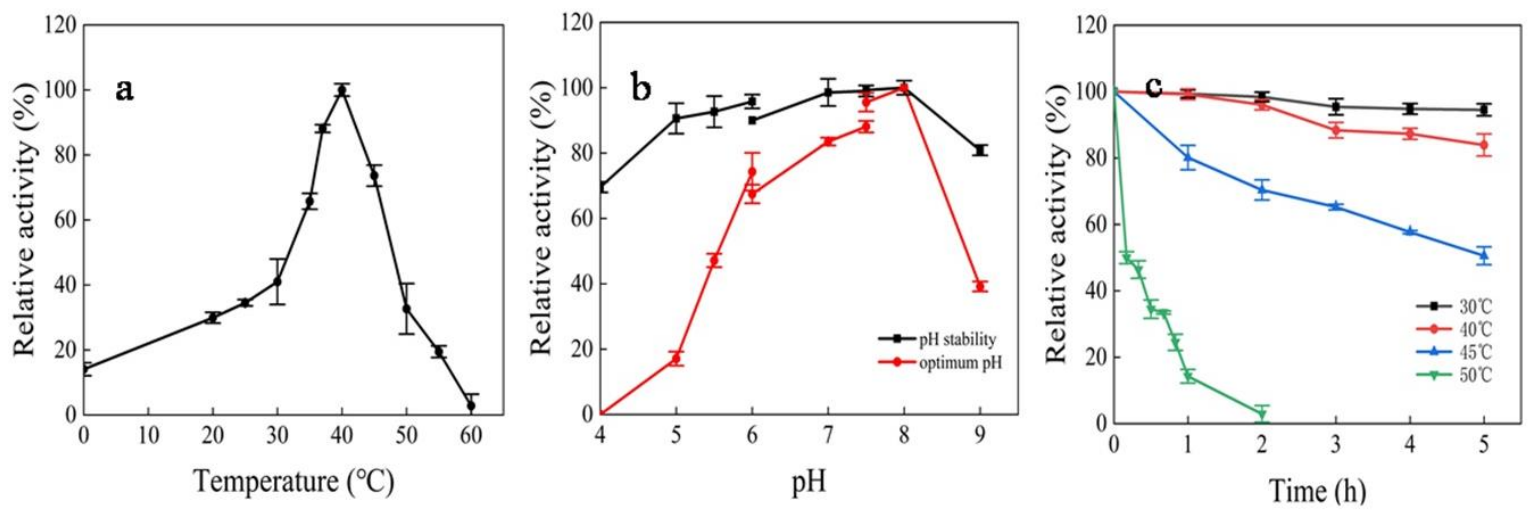

Figure 7. Effects of temperature (a) and $\mathrm{pH}(\mathbf{b})$ on dextranase activity and stability (c). For each effect on dextranase activity, the values are shown as percentages of the maximum activities, which were taken as $100 \%$.

\subsubsection{Effects of Metal Ions and Reagents on Dextranase Activity}

The effect of metal ions on dextranase activity is shown in Table 3. In the presence of metal ions $\mathrm{Sr}^{2+}$, the dextranase activity increased from $100 \%$ (without adding compounds) to $128.71 \%$, and the metal ions $\mathrm{NH}^{4+}, \mathrm{Ni}^{2+}, \mathrm{Cd}^{2+}, \mathrm{Fe}^{3+}, \mathrm{Li}^{+}, \mathrm{Cu}^{2+}$, and $\mathrm{Co}^{2+}$ had a strong inhibitory effect on dextranase activity. Metal ions such as $\mathrm{Ca}^{2+}, \mathrm{K}^{+}, \mathrm{Zn}^{2+}, \mathrm{Mg}^{2+}$, and $\mathrm{Ba}^{2+}$ did not have a significant inhibitory effect. Moreover, the main compounds in dental care products, such as sodium fluoride, xylitol, sodium 
benzoate, lauric acid, and ethanol, had no significant effect on dextranase activity. However, we found that $1 \mathrm{mM}$ sodium dodecyl sulfate (SDS) had a certain inhibitory effect on dextranase activity (Table 4), which was similar to results reported by Ren Wei et al. [35].

Table 3. Effect of metal ions on dextranase.

\begin{tabular}{ccc}
\hline Reagents & Relative Activity (\%) $\mathbf{( 1} \mathbf{~ m M )}$ & Relative Activity $\mathbf{( \% )}(\mathbf{5} \mathbf{~ m M})$ \\
\hline Control & $100.00 \pm 0.07$ & $100.00 \pm 0.07$ \\
$\mathrm{Ca}^{2+}$ & $95.80 \pm 0.56$ & $100.87 \pm 0.12$ \\
$\mathrm{Ba}^{2+}$ & $97.35 \pm 1.10$ & $83.96 \pm 0.48$ \\
$\mathrm{Mg}^{2+}$ & $88.36 \pm 0.86$ & $76.62 \pm 2.12$ \\
$\mathrm{NH}^{4+}$ & $65.56 \pm 1.24$ & $69.37 \pm 1.06$ \\
$\mathrm{Ni}^{2+}$ & $76.57 \pm 0.98$ & $78.81 \pm 2.43$ \\
$\mathrm{Cd}^{2+}$ & $0.25 \pm 0.37$ & 0.00 \\
$\mathrm{Fe}^{3+}$ & $76.62 \pm 2.46$ & 0.00 \\
$\mathrm{Co}^{2+}$ & $72.68 \pm 2.16$ & $29.14 \pm 1.59$ \\
$\mathrm{Cu}^{2+}$ & $70.23 \pm 2.57$ & $12.35 \pm 2.81$ \\
$\mathrm{Sr}^{2+}$ & $96.83 \pm 2.76$ & $128.71 \pm 1.49$ \\
$\mathrm{~K}^{+}$ & $98.30 \pm 2.58$ & $102.10 \pm 1.71$ \\
$\mathrm{Li}^{+}$ & 0.00 & 0.00 \\
$\mathrm{Zn}^{2+}$ & $93.64 \pm 1.44$ & $86.73 \pm 0.81$ \\
\hline
\end{tabular}

Table 4. Effect of dental caries chemical treatment reagents on dextranase activity. SDS, sodium dodecyl sulfate.

\begin{tabular}{cc}
\hline Reagents $(w / v)$ & Relative Activity (\%) \\
\hline Control & $100.00 \pm 0.30$ \\
$0.1 \%$ sodium fluoride & $106.64 \pm 2.49$ \\
$0.1 \%$ xylitol & $103.75 \pm 1.23$ \\
$0.1 \%$ sodium benzoate & $102.14 \pm 1.67$ \\
$5 \%$ ethanol & $88.80 \pm 3.38$ \\
1 mM SDS & $52.74 \pm 3.05$ \\
$1 \%$ lauric acid & $91.20 \pm 0.27$ \\
\hline
\end{tabular}

\subsubsection{Substrate Specificity and Final Hydrolysis Products}

The substrate specificity of dextranase was evaluated using materials with different glucosidic linkages (Table 5). Dextranase had high specificity for dextran containing $\alpha$-1,6-glucosidic linkages. When the substrate concentration was 3\%, the optimal substrate was dextran T500. However, the dextranase had poor hydrolysis ability for soluble starch, even though the soluble starch was composed of $\alpha-1,4$-glucosidic bonds. Pullulan, chitin, cyclodextrin, and mannan are mainly composed of $\alpha$-1,4-glucosidic bonds, and the dextranase was unable to hydrolyze them, either. High-performance liquid chromatography (HPLC) showed that maltoheptaose, glucose, and maltose were the main hydrolysates of dextranase (Figure 8). Moreover, the peak area of the hydrolysate detected by HPLC was quantified using Empower GPC software (Gel Permeation Chromatography-GPC) (Table 6). When the hydrolysis reaction time was extended from $0.5 \mathrm{~h}$ to $3 \mathrm{~h}$, the amount of maltotriose and maltotetraose decreased slightly, which was similar to results reported in the literature [35,36]. This indicated that dextranase is an endotype dextranase. 
Table 5. Action of dextranase on diverse carbohydrates.

\begin{tabular}{ccc}
\hline Substrate & Main Linkages & Relative Activity (\%) \\
\hline DextranT20 & $\alpha-1,6$ & $73.79 \pm 0.52$ \\
DextranT40 & $\alpha-1,6$ & $72.28 \pm 0.39$ \\
DextranT70 & $\alpha-1,6$ & $99.56 \pm 0.61$ \\
DextranT500 & $\alpha-1,6$ & $100.00 \pm 0.25$ \\
DextranT2000 & $\alpha-1,6$ & $95.10 \pm 0.72$ \\
Soluble starch & $\alpha-1,4, \alpha-1,6$ & $4.47 \pm 0.49$ \\
Pullulan & $\alpha-1,4$ & 0.00 \\
Chitin & $\alpha-1,4$ & 0.00 \\
Sucrose & $\alpha-1,2$ & 0.00 \\
$\beta$-cyclodextrin & $\alpha-1,4$ & 0.00 \\
mannan & $\alpha-1,4$ & 0.00 \\
Sephadex G-100 & $\alpha-1,6$ & $82.24 \pm 0.27$ \\
Sephadex G-200 & $\alpha-1,6$ & $75.56 \pm 0.38$ \\
\hline
\end{tabular}

Table 6. Proportion of products of hydrolyzed dextran.

\begin{tabular}{cccccc}
\hline \multirow{2}{*}{ Time of Hydrolysis } & \multicolumn{5}{c}{ Hydrolysis Productions (\%) } \\
\cline { 2 - 6 } & Glucose & Maltose & Maltotriose & Maltotetraose & Maltoheptaose \\
\hline $0.5 \mathrm{~h}$ & 19.16 & 10.24 & 6.84 & 4.96 & 58.93 \\
$3 \mathrm{~h}$ & 26.06 & 13.56 & 2.24 & 2.83 & 55.42 \\
\hline
\end{tabular}
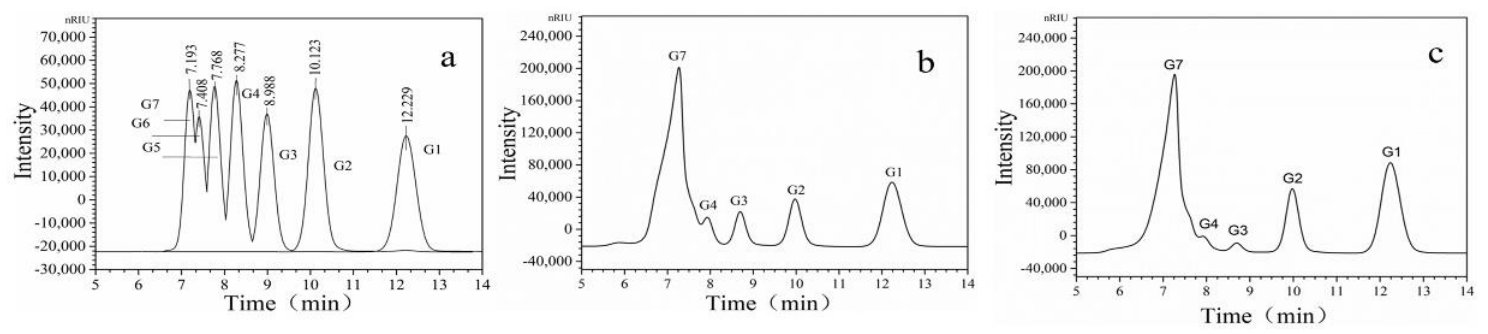

Figure 8. The product of dextranase and $3 \%$ dextran T50 reacted at $40{ }^{\circ} \mathrm{C}$ for different times was measured by high-performance liquid chromatography (HPLC): (a) standard results (G1 to G7) were glucose, maltose, maltotriose, maltotetraose, maltopentaose, maltohexaose, and maltoheptaose standard sugar, (b) the results of dextranase hydrolyzed to 3\% dextran $7500.5 \mathrm{~h}$, (c) the results of dextranase hydrolyzed to $3 \%$ dextran T50 $3 \mathrm{~h}$.

\subsection{Effect of Dextranase on Plaque}

Streptococcus mutans is considered to be one of the important bacteria responsible for forming dental plaque and caries. To investigate the inhibition of dextranase on the biofilm formation of S. mutans, the minimally biofilm inhibitory concentration (MBIC) of this enzyme was determined (Table 7). The results showed that the experimental groups were significantly different from the control group, indicating that dextranase has a remarkable inhibitory effect on the formation of plaque. As the concentration of dextranase increased, the amount of plaque formed gradually decreased. When the dextranase concentration was $3 \mathrm{U} / \mathrm{mL}$ and $7 \mathrm{U} / \mathrm{mL}$, the plaque inhibition rate was $52.3 \%$ and $91.79 \%$, respectively.

The results of the scanning electron microscopy (SEM) showed that the structure of the plaque without the addition of dextranase was tight, and the extracellular polysaccharide and bacteria interweaved to form many channels (Figure 9). When the concentration of dextranase was continuously increased, the adhesion of bacteria decreased, the biofilm gradually became thinner, and the structure became looser. The micro-plate crystal violet staining combined with scanning electron microscopy showed that the dextranase significantly inhibited the plaque formed by S. mutans. 
The biofilm inhibitory rate was calculated at an absorbance of $595\left(\mathrm{~A}_{595}\right)$ of the crystal-violet-stained biofilm without dextranase subtracted from $\mathrm{A}_{595}$ of the biofilm with dextranase, and divided by $\mathrm{A}_{595}$ of the biofilm without dextranase multiplied by $100 \%$.

Table 7. Biofilm inhibitory rates at different concentrations of dextranase.

\begin{tabular}{cc}
\hline Addition of Dextranase (U/mL) & Biofilm Formation Inhibition Rate (\%) \\
\hline 0 & $0.00 \pm 0.79$ \\
1 & $23.03 \pm 1.08$ \\
2 & $35.18 \pm 0.85$ \\
3 & $52.30 \pm 2.04$ \\
4 & $54.21 \pm 1.45$ \\
5 & $74.74 \pm 0.74$ \\
6 & $87.12 \pm 0.81$ \\
7 & $91.79 \pm 0.68$ \\
\hline
\end{tabular}
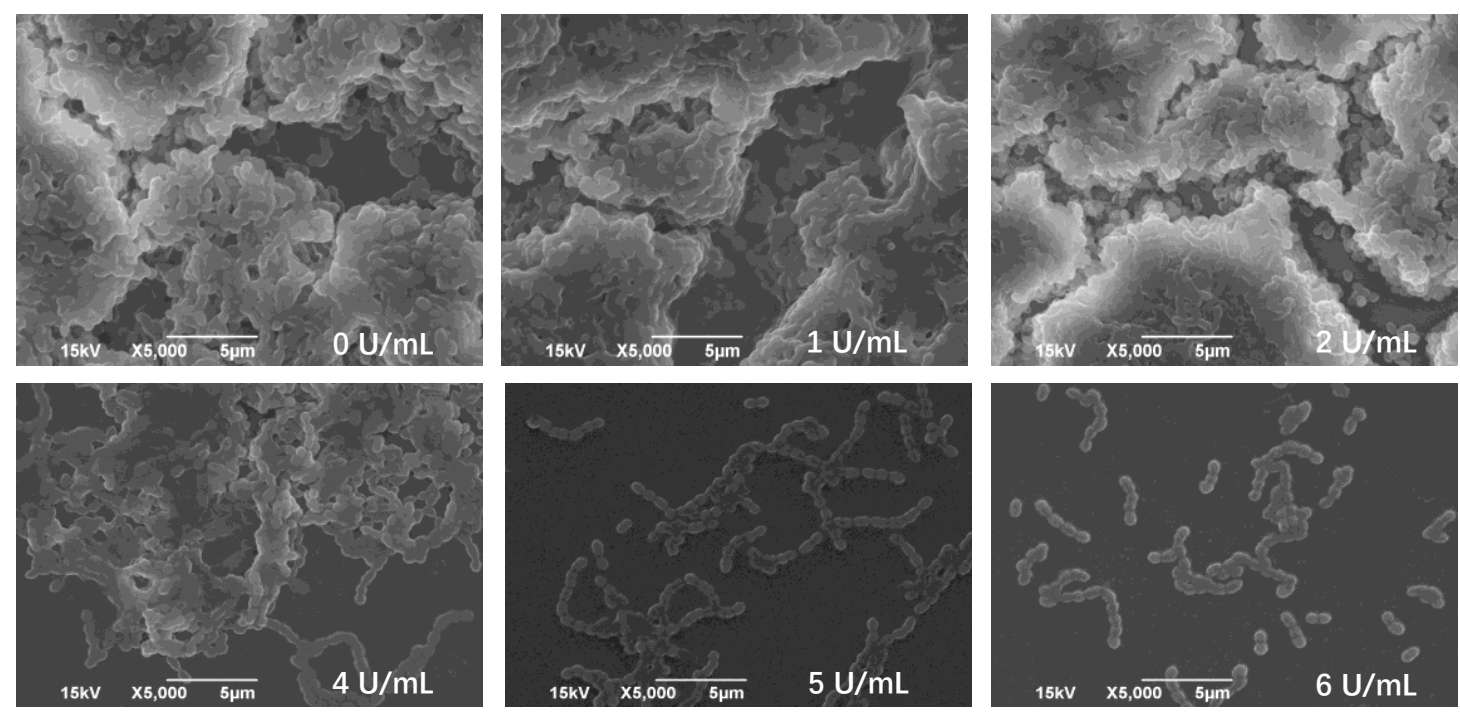

Figure 9. Electron microscopy was used to analyze the effects of different concentrations of dextranase on the biofilm formation of Streptococcus mutans on sterile coverslips. Here, $0 \mathrm{U} / \mathrm{mL}$ represents a blank control, adding an equal amount of sterile pure water instead of dextranase, and others represent biofilms under the action of $1,2,4,5$, and $6 \mathrm{U} / \mathrm{mL}$ dextranase, respectively.

\section{Discussion}

Dental caries is a chronic disease affecting different population groups all over the world. Moreover, plaque supports bacteria in etching the teeth $[17,32]$. Dextranase can remove plaque, but it is still a challenge to find a dextranase that is suitable for use in oral products. Compared with terrestrial-derived biological enzymes, marine enzymes are more suitable for industrial applications because of their salt tolerance, low temperature resistance, and alkali resistance $[33,34]$.

Catenovulum sp. is a new type of marine bacteria found in the marine environment in recent years, so there is little information on its properties, and there are few strains that produce dextranase. Compared with fungi and actinomycetes [27], bacterial fermentation production of dextranase has the advantages of a short fermentation time and a low temperature, which can save energy, manpower, and time in industrial applications. C. agarivorans MNH15 did not grow in the broth absence of $\mathrm{NaCl}$, indicating that the strain is a halophilic bacterium that grows better at a $\mathrm{pH}$ of $8-9$, and like C. agarivorans $[37,38]$. Compared with terrestrial bacteria, most marine bacteria are oligotrophic, and the enzyme-producing medium components are relatively easy to get, so C. agarivorans MNH15 has strong potential for application in industry settings [27,39,40]. 
The molecular weight of dextranase of bacteria was found to be between 60 and $114 \mathrm{KDa}$ [27,41], and Koenig and Day found that the molecular weight of fungi was at least $23 \mathrm{KDa}$ [42]. In contrast, we found that the molecular weight of dextranase produced by C. agarivorans MNH15 was about $110 \mathrm{KDa}$. The bacterium of the same genus, Catenovulum sp. DP03, was found to have a molecular weight of about $75 \mathrm{KDa}$ [35]. Thus, further research on the structure of dextranase may contribute to a better understanding of biochemistry and biocatalysis. The optimal $\mathrm{pH}$ of dextranase was found to be 8.0. Moreover, the $\mathrm{pH}$ of the dextranase produced by most strains, such as Arthrobacter sp. Arth410 [43] and T. pinophilus H6 [27], was acidic. Our dextranase also had a lower $\mathrm{pH}$ sensitivity, indicating that the alkaline dextranase is suitable for mouth products $[32,44,45]$. The dextranase had good catalytic activity at a temperature range of $35^{\circ} \mathrm{C}-45^{\circ} \mathrm{C}$, which is similar to human body temperature, indicating that it can be applied to the development of oral care products.

The activity of dextranase increased to $128.71 \%$ under the treatment of $5 \mathrm{mM} \mathrm{SrCl}_{2}$, which was consistent with the results reported by Wu et al. [17,39,45,46]. The same concentration of $\mathrm{SrCl}_{2}$ had little effect on the activity of dextranase produced by the same genus Catenovulum sp. DP03 bacteria, reported by Ren Wei et al. [35]. Moreover, $\mathrm{MgCl}_{2}, \mathrm{NH}_{4} \mathrm{Cl}$, and $\mathrm{NiCl}_{2}$ only had a slight effect on dextranase activity, whereas $\mathrm{CaCl}_{2}, \mathrm{BaCl}_{2}, \mathrm{KCl}$, and $\mathrm{ZnSO}_{4}$ had no significant effect on the activity of dextranase. The characteristics will benefit the application of oral care products [27]. The products of MNH15-dextranase-catalyzed substrate hydrolysis were mainly glucose, maltose, maltotetraose, and maltoheptaose, which was slightly different compared with other sources of dextranases $[35,40,47,48]$. The main hydrolysate of Catenovulum sp. DP03 dextranase was isomalto-oligosaccharide, which produces a small amount of glucose over time [35]. The hydrolysates of T. pinophilus dextranase reported by Yu-Qi Zhang et al. were isomaltose and a small amount of isomalto-oligosaccharide [27].

We found that several reagents commonly used in dental care products, such as ethanol, sodium fluoride, xylitol, lauric acid, and sodium benzoate, had no significant effect of the dextranase activity. The enzyme produced by marine microorganisms was a biologically active metabolite with excellent thermal stability, salt tolerance, and low temperature resistance [49-51]. The characteristics of dextranase imply an advantage when it is used in oral care products to remove plaque and prevent dental caries.

\section{Materials and Methods}

\subsection{Samples and Chemicals}

Sea mud, seaweed, and seawater samples were collected from Haizhou Bay in Jiangsu, China. Dextran (T20, T40, T70, T500) and blue dextran 2000 were obtained from GE Healthcare (Uppsala, Sweden). All other reagents were purchased from Sinopharm Chemical Reagent Corp. (Shanghai, China) and were of analytical grade.

\subsection{Isolation of Dextranase-Producing Marine Bacterial Strains}

We used a blue dextran plate to screen marine bacteria-produced dextranase. The screening medium plates contained $10 \mathrm{~g}$ dextran, $1 \mathrm{~g}$ yeast extract, $5 \mathrm{~g}$ peptone, $2 \mathrm{~g}$ blue dextran 2000, $20 \mathrm{~g}$ agar powder, and $1 \mathrm{~L}$ aged sea water, at an initial $\mathrm{pH}$ of 8.0. We diluted the sample suspension with an appropriate amount of sterile distilled water and spread it evenly on a blue dextran plate. After incubating it for $2 \mathrm{~d}$ at $25^{\circ} \mathrm{C}$, the strain producing dextranase was selected according to a transparent zone around the colony. The colony diameter and the diameter of the transparent zone of the target strain on the plate were measured, and the hydrolysis ability was determined by the square of their ratios. The selected strains were inoculated into the fermentation shake flask (excluding agar and blue dextran 2000), and after fermentation at $180^{\circ} \mathrm{C}$ for $48 \mathrm{~h}$ at $25^{\circ} \mathrm{C}$, the dextranase activity was measured using a standard method, and the strain with the highest enzyme production rate was selected. 


\subsection{Identification and Characterization of Bacteria}

The phenotypic characteristics of strain MNH15 were identified by observing colony morphology, light microscopy, and SEM. We then identified various physiological and biochemical reactions according to the Berger Bacterial Identification Manual (9th Edition, Baltimore: Williams \& Wilkins). The genome of strain MNH15 was extracted with the bacterial genome extraction kit, and the 16S-rDNA gene was amplified with primers 27F (5'-AGAGTTTGATCCTGGCTCAG-3') and 1492R (5'-GGTTACCTTGTTACGACTT-3'). The PCR product was gel-recovered, connected with pMD19-T vector (Takara Bio Inc. Japan), and transferred to DH5a-competent cells. The positive clones were then screened by blue and white spots. The extracted colony plasmids were verified using agarose gel and sent for sequencing (Sangon, Shanghai, China). The 16S-rDNA gene sequence was analyzed by BLAST analysis with the existing sequence in GenBank, and the phylogenetic tree was constructed using the neighbor-joining method to determine the taxonomic status of the strain.

After the seed was activated, the cells were cultured at different temperatures $\left(0{ }^{\circ} \mathrm{C}-45^{\circ} \mathrm{C}\right)$ to determine the optimal growth temperature. In order to prevent $\mathrm{pH}$ changes during the culture, different buffers (MES buffer, $\mathrm{pH}$ 5.0-6.0; PIPES buffer, $\mathrm{pH}$ 6.5-7.0; HEPES buffer, $\mathrm{pH}$ 9.0-11.0) with a final concentration of $10 \mathrm{mmol} / \mathrm{L}$ were added to the medium to maintain the $\mathrm{pH}$ range of $4.0-10.0$, and the culture was carried out at the optimum temperature. The medium was prepared with a trace-salt solution (without $\mathrm{NaCl}$ ), and the $\mathrm{NaCl}$ concentration ranged from 0 to $100 \mathrm{~g} / \mathrm{L}$. It was then cultured under optimum temperature and $\mathrm{pH}$ conditions. The logarithmic growth phase of strain MNH15 included inoculating the 3\% seed solution, and the absorbance at a wavelength of $600 \mathrm{~nm}$ was measured every $3 \mathrm{~h}$ under optimal growth conditions. The optimal culture time for producing dextranase was in the range of $0 \mathrm{~h}$ and $72 \mathrm{~h}$. After $12 \mathrm{~h}$ of culturing, samples were taken every $6 \mathrm{~h}$, and the enzyme activity was measured under standard conditions.

\subsection{Culture Conditions for Dextranase Production and Purification}

The culture medium for producing dextranase comprised $5 \mathrm{~g}$ of yeast extract, $5 \mathrm{~g}$ of peptone, $10 \mathrm{~g}$ of dextran, and $1 \mathrm{~L}$ of aged seawater, at an initial $\mathrm{pH}$ of 8.0. After the strain was activated, the inoculated medium was cultured at $30^{\circ} \mathrm{C}$ at $180 \mathrm{rpm}$ for $48 \mathrm{~h}$, the fermentation broth was centrifuged $\left(10,000 \mathrm{rpm}, 30 \mathrm{~min}, 4^{\circ} \mathrm{C}\right)$, and the supernatant was taken to determine the dextranase activity. Then, the supernatant was filtered through a $0.45 \mu \mathrm{m}$ membrane, ultra-filtered using a hollow fiber column, and a molecular weight of $30 \mathrm{KDa}$ was cut off. After being purified, the freeze-dried powder was prepared using a freeze-drying machine (Labconco Corp., Kansas City, MO, USA).

\subsection{Enzyme Assay}

Then, $50 \mu \mathrm{L}$ of the enzyme solution was added into $150 \mu \mathrm{L}$ of $3 \%$ dextran T20 (50 mM, pH 8.0 Tris- $\mathrm{HCl}$ buffer), and kept at $40^{\circ} \mathrm{C}$ for $15 \mathrm{~min}$. The amount of reducing sugar was determined using the 3,5-dinitrosalicylic acid (DNS) method. The enzyme activity dictated that, under the above reaction conditions, the amount of enzyme required to catalyze the release of $1 \mu \mathrm{mol}$ of maltose per minute was one unit of activity [52].

\subsection{Conditions Needed for Producing Dextranase}

\subsubsection{Effects of Different Carbon and Nitrogen Sources on Dextranase Production}

The yeast extract and peptone in the fermentation medium were replaced by a common carbon source of $10 \mathrm{~g} / \mathrm{L}$ and a common nitrogen source of $5 \mathrm{~g} / \mathrm{L}$, respectively. After being cultured at $30^{\circ} \mathrm{C}$, $180 \mathrm{rpm}$ for $48 \mathrm{~h}$, the supernatant of the fermentation broth was taken to determine the activity of dextranase. 


\subsubsection{Effects of Temperature, Initial $\mathrm{pH}$, and $\mathrm{NaCl}$ Concentration on Dextranase Production}

The culture medium was incubated at different temperatures $\left(15^{\circ} \mathrm{C}-40^{\circ} \mathrm{C}\right)$ for $48 \mathrm{~h}$ under the previously mentioned optimal medium. The initial $\mathrm{pH}$ of the fermentation medium (5.0-10.0) was adjusted to determine the optimal initial $\mathrm{pH}$ of the enzyme produced by the strain and incubated at $30{ }^{\circ} \mathrm{C}$ for $48 \mathrm{~h}$. Different concentrations of $\mathrm{NaCl}$ were added to the medium, and the fermentation was carried out at an optimal temperature, $\mathrm{pH}$, and time. The enzyme activity was then measured using a standard method.

\subsubsection{Effect of Inoculum, Aeration, and Inducer Concentration on Dextranase Production}

The seed solution was inoculated into the fermentation shake flask according to different amounts $(1 \%-6 \%)$. The different volumes of medium $(20-90 \mathrm{~mL})$ were then added in a $250 \mathrm{~mL}$ Erlenmeyer flask. Dextran 20000 was used as an inducer to induce the production of dextranase, and different concentrations of dextran $(0 \%-1.6 \%)$ were then added. Then, we detected the dextranase of the supernatant.

\subsection{Enzyme Preparation and In-Gel Activity Assay}

The supernatant was lyophilized and stored at $-20^{\circ} \mathrm{C}$. The molecular mass of dextranase was visualized through SDS-polyacrylamide gel electrophoresis (PAGE). The activity level of dextranase in the gel was determined by an $8 \%$ native PAGE gel containing $0.5 \%$ blue dextran.

\subsubsection{Effects of Temperature on Dextranase Activity and Stability}

In order to evaluate the effect of temperature on the activity of the enzyme, the enzyme activity after incubation at $20{ }^{\circ} \mathrm{C}-60{ }^{\circ} \mathrm{C}$ was measured. The relative residual activity of dextranase was determined through a standard method after leaving the enzyme solution at different temperatures $\left(30{ }^{\circ} \mathrm{C}, 40^{\circ} \mathrm{C}, 50^{\circ} \mathrm{C}\right)$ without adding substrate for $1-5 \mathrm{~h}$ to investigate the thermal stability of the enzyme. The percentage of the maximum enzyme activity indicated the relative activity.

\subsubsection{Effect of $\mathrm{pH}$ on Dextranase Activity and Stability}

Determination of dextranase activity at different $\mathrm{pH}$ values ranging from 4.0 to 9.0 (acetate buffer, $\mathrm{pH}$ 3.0-5.5; phosphate buffer, $\mathrm{pH} 6.0-8.0$; Tris-HCl, $\mathrm{pH} 7.5-9.0$ ) and at $40^{\circ} \mathrm{C}$. To evaluate the $\mathrm{pH}$ stability of dextranase in the absence of substrate, the dextranase was placed in a buffer of $\mathrm{pH}$ 4.0-9.0 at $25^{\circ} \mathrm{C}$ for $1 \mathrm{~h}$. Using dextran 20000 as a substrate, we measured the residual viability of the enzyme under standard conditions.

\subsubsection{Effects of Metal Ions and Other Reagents on Dextranase Activity}

Next, we measured the effects of the following metal ions and reagents on dextranase activity: $\mathrm{Ca}^{2+}\left(\mathrm{CaCl}_{2}\right), \mathrm{Ba}^{2+}\left(\mathrm{BaCl}_{2}\right), \mathrm{Mg}^{2+}\left(\mathrm{MgCl}_{2}\right), \mathrm{NH}_{4}{ }^{+}\left(\mathrm{NH}_{4} \mathrm{Cl}\right), \mathrm{Ni}^{2+}\left(\mathrm{NiCl}_{2}\right), \mathrm{Fe}^{3+}\left(\mathrm{FeCl}_{3}\right), \mathrm{Co}^{2+}\left(\mathrm{CoCl}_{2}\right)$, $\mathrm{Cu}^{2+}\left(\mathrm{CuSO}_{4}\right), \mathrm{K}^{+}(\mathrm{KCl}), \mathrm{Zn}^{2+}\left(\mathrm{ZnSO}_{4}\right), \mathrm{Sr}^{2+}\left(\mathrm{SrCl}_{2}\right), \mathrm{Li}^{+}(\mathrm{LiCl}), \mathrm{Cd}^{2+}\left(\mathrm{CdCl}_{2}\right)$, sodium fluoride, xylitol, sodium benzoate, ethanol, sodium dodecyl sulfonate, and lauric acid. The metal ions were set at two different concentrations.

\subsubsection{Substrate Specificity and Analysis of Final Hydrolysis Products}

The substrate of the different glucosidic linkages was reacted with dextranase at $40{ }^{\circ} \mathrm{C}$ for $15 \mathrm{~min}$, and the enzyme activity was measured. The relative enzyme activity was expressed at $100 \%$ of the maximum enzyme activity.

The final hydrolysis products of dextran were analyzed using HPLC. Then, $300 \mu \mathrm{L}$ dextranase was reacted with $900 \mu \mathrm{L} \mathrm{3} \%$ dextran T50 at $40{ }^{\circ} \mathrm{C}$ for $0.5 \mathrm{~h}$ and $3 \mathrm{~h}$, respectively. Then, the solution was boiled for $5 \mathrm{~min}$ to denature dextranase and centrifuged at 10,000 rpm for $10 \mathrm{~min}$. The supernatant was filtered through a $0.45 \mu \mathrm{m}$ filter. The products were identified and analyzed with the Waters 
600 and Waters Sugar-Pak1 $(6.5 \times 300 \mathrm{~mm}$; Waters, Milford, MA, USA) HPLC with a differential refraction detector. The mobile phase was water at $0.4 \mathrm{~mL} / \mathrm{min}$. The column temperature was $75{ }^{\circ} \mathrm{C}$. The injection volume was $20 \mu \mathrm{L}$. The standard substances were Glucose (glycarbo\#GY1107-500 g 99\%), Maltotriose (glycarbo\#GY1063-5 g 97\%), Maltotetraose (glycarbo\#GY1064-50 mg 97\%), Maltopentaose (glycarbo\#GY1065-50 mg 97\%), Maltohexaose (glycarbo\#GY1066-50 mg 95\%), and Maltoheptaose (glycarbo\#GY1067-50 mg 95\%), respectively. Quantification was based on calculation of the peak areas. Data acquisition and processing were conducted using Empower GPC software (Waters, Milford, MA, USA).

\subsection{Effect of Dextranase on Plaque Formation}

The effect of dextranase on the biofilms produced by S. mutans ATCC 25175 (American Type Culture Collection (ATCC), Manassas, VA, USA) was investigated using the microplate method and SEM. The $S$. mutans were first pre-incubated in a sucrose-free brain heart infusion (BHI) medium at $37^{\circ} \mathrm{C}$ for $18 \mathrm{~h}$, and then $600 \mu \mathrm{L}$ of activated seed solution was inoculated into microplates containing a $1 \%$ sucrose BHI medium (Greiner, Frickhausen, Germany). The minimally biofilm inhibitory concentration (MBIC) of the drug was assessed. Microplates were used to measure the biofilm quality of the crystal violet stain in which the biofilm was grown, and then the medium was removed from the microplates containing $1 \%$ sucrose BHI medium (contains different concentrations of dextranase) [53]. Then, we slowly added $0.2 \mathrm{~mL}$ of a phosphate buffer three times to each well to remove the poorly adsorbed biofilm and medium, and let it dry naturally for $1 \mathrm{~h}$. Then, $0.2 \mathrm{~mL}$ of the $0.1 \%$ crystal violet solution was slowly added to each well for $5 \mathrm{~min}$, and excess solution was removed and washed three times with a phosphate buffer. After drying, $0.2 \mathrm{~mL}$ of $95 \%$ ethanol was added to re-dissolve the stained biofilm. Finally, the absorbance at $595 \mathrm{~nm}$ was measured on a microplate reader (model 3550; Bio-Rad Laboratories, Richmond, CA, USA). The measurement was repeated three times and averaged, and then we measured the biofilm formation inhibition rate $\%=(1-$ experimental group/control group) $\times 100$ [54].

The sterile slides were placed in a 24 -well cell culture plate, and $1 \mathrm{~mL}$ of $0.2 \%$ sterile gelatin was added for $12 \mathrm{~h}$ and then aspirated. The $S$. mutans seed solution and the brain-heart leaching solution (BHI) medium containing $1 \%$ sucrose were added to the gelatin-treated 24-well plate in a ratio of 1:9, and the final concentration of the dextranase was $0.1,2,4,5,6 \mathrm{U} / \mathrm{mL}$. After anaerobic incubation for $24 \mathrm{~h}$ at $37^{\circ} \mathrm{C}$, the slides were removed, gently washed with sterile water, fixed overnight with $2.5 \%$ glutaraldehyde, and dehydrated with different concentrations of alcohol gradient. The samples were then dried and sprayed with gold before we observed and detected them by SEM (Model JFC-1600, JSM-6390LA; JEOL, Tokyo, Japan) [43,55].

\section{Conclusions}

In summary, the dextranase-producing MNH15 strain of $C$. agarivorans was screened from marine samples. A higher yield of dextranase was produced when the temperature, initial $\mathrm{pH}$, $\mathrm{NaCl}$ concentration, and inducer concentration were $30^{\circ} \mathrm{C}, 8.0,5 \mathrm{~g} / \mathrm{L}$, and $8 \mathrm{~g} / \mathrm{L}$, respectively. The maximum enzyme activity was performed at $40^{\circ} \mathrm{C}$ and a pH of 8.0. The dextranase exhibited excellent thermostability and stability at a wide range of $\mathrm{pH}$ values (4.0-9.0). The molecular weight of dextranase was around $110 \mathrm{kDa}$. Sodium fluoride, xylitol, and sodium benzoate, all used in dental care products, had no significant effect on the activity of the dextranase. The result of the HPLC showed that dextran was mainly hydrolyzed to glucose, maltose, and maltoheptaose. Moreover, the dextranase effectively inhibited the formation of biofilm by S. mutans. Therefore, dextranase has strong application potential in dental products formulated to remove dental plaque. 
Author Contributions: X.L. (Xiaohua Lai), X.L. (Xin Liu), X.L. (Xueqin Liu), M.L., and S.W. designed the experiments. X.L. (Xiaohua Lai), X.L. (Xin Liu), X.L. (Xueqin Liu), T.D., Y.F., and X.T. performed the experiments. X.L. (Xiaohua Lai), X.L. (Xin Liu), T.D., Y.F., X.T., and M.L. analyzed the data. S.W. and M.L. supervised the study and reviewed the manuscript. X.L. (Xiaohua Lai) and X.L. (Xin Liu) wrote the manuscript. All authors have read and approved the final manuscript.

Funding: The research was funded by the National Key R\&D Program of China, grant number 2018YFC0311106, the Key Research and Development Program of Jiangsu [Social Development], grant number BE2016702, the Priority Academic Program Development of Jiangsu Higher Education Institutions, grant number PAPD, and the Postgraduate Research \& Practice Innovation Program of Jiangsu Province, grant number SJCX18_0948.

Conflicts of Interest: The authors confirm that there is no conflict of interests regarding this paper.

Ethical Approval: This article does not contain any studies with animals performed by any of the authors.

\section{References}

1. Monsan, P.; Bozonnet, S.; Albenne, C.; Joucla, G.; Willemot, R.M.; Remaud-Siméon, M. Homopolysaccharides from lactic acid bacteria. Int. Dairy J. 2001, 11, 675-685. [CrossRef]

2. Kim, D.; Robyt, J.F.; Lee, S.Y.; Lee, J.H.; Kim, Y.M. Dextran molecular size and degree of branching as a function of sucrose concentration, $\mathrm{pH}$, and temperature of reaction of Leuconostoc mesenteroides B-512FMCM dextransucrase. Carbohydr. Res. 2003, 338, 1183-1189. [CrossRef]

3. Zou, Q.; Pu, Y.; Han, Z.; Fu, N.; Li, S.; Liu, M.; Huang, L.; Lu, A.; Mo, J.; Chen, S. Ultrasonic degradation of aqueous dextran: Effect of initial molecular weight and concentration. Carbohydr. Polym. 2012, 90, 447-451. [CrossRef] [PubMed]

4. Marsh, P.D. Controlling the oral biofilm with antimicrobials. J. Dent. 2010, 38, S11-S15. [CrossRef]

5. Johansen, C.; Falholt, P.; Gram, L. Enzymatic removal and disinfection of bacterial biofilms. Appl. Environ. Microbiol. 1997, 63, 3724-3728. [PubMed]

6. Sims, I.M.; Thomson, A.; Hubl, U.; Larsen, N.G.; Furneaux, R.H. Characterisation of polysaccharides synthesised by Gluconobacter oxydans NCIMB 4943. Carbohydr. Polym. 2001, 45, 285-292. [CrossRef]

7. Moriyama, K.; Yui, N. Regulated insulin release from biodegradable dextran hydrogels containing poly(ethylene glycol). Control. Release 1996, 42, 237-248. [CrossRef]

8. Salassi, M.; Garcia, M.; Breaux, J.; No, S. Impact of Sugarcane Delivery Schedule on Product Value at Raw Sugar Factories. J. Agribus. 2004, 22, 47-54.

9. Brown, C.F.; Inkerman, P.A. Specific method for quantitative measure of the total dextran content of raw sugar. J. Agric. Food Chem. 1992, 40, 227-233. [CrossRef]

10. McCoy, L.C.; Wehler, C.J.; Rich, S.E.; Garcia, R.I.; Miller, D.R.; Jones, J.A. Adverse events associated with chlorhexidine use: Results from the Department of Veterans Affairs Dental Diabetes Study. Am. Dent. Assoc. 2008, 139, 178-183. [CrossRef]

11. Grover, R.; Frank, M.E. Regional Specificity of Chlorhexidine Effects on Taste Perception. Chem. Senses 2008, 33, 311-318. [CrossRef] [PubMed]

12. Khalikova, E.; Susi, P.; Korpela, T. Microbial Dextran-Hydrolyzing Enzymes: Fundamentals and Applications. Microbiol. Mol. Biol. Rev. 2005, 69, 306-325. [CrossRef] [PubMed]

13. Reese, E.; Lola, J.; Parrish, F. Modified Substrates and Modified Products as Inducers of Carbohydrases. J. Bacteriol. 1970, 100, 1151-1154.

14. Brown, R.G. Stimulation of dextranase production by oxidized dextran. Can. J. Microbiol. 1970, 16, 841-844. [CrossRef]

15. Thitaram, S.N.; Chung, C.H.; Day, D.F.; Hinton, A.; Bailey, J.S.; Siragusa, G.R. Isomaltooligosaccharide increases cecal Bifidobacterium population in young broiler chickens. Poult. Sci. 2005, 84, 998-1003. [CrossRef]

16. Eggleston, G.; Monge, A.; Montes, B.; Stewart, D. Application of dextranases in sugarcane factory: Overcoming practical problems. Sugar Tech 2009, 11, 135-141. [CrossRef]

17. Eggleston, G.; Dilks, A.; Blowers, M.; Winters, K. Successful application of dextranase in sugar beet factories. In Proceedings of the American Society of Sugarbeet Tchnologist, Albuquerque, NM, USA, 2-5 March 2011; pp. 1-16.

18. Erhardt, F.A.; Jöerdening, H.-J. Immobilization of dextranase from Chaetomium erraticum. J. Biotechnol. 2007, 131, 440-447. [CrossRef] 
19. Anderson, K.; Li, S.C.; Li, Y.T. Diphenylamine-aniline-phosphoric acid reagent, a versatile spray reagent for revealing glycoconjugates on thin-layer chromatography plates. Anal. Biochem. 2000, 287, 337-339. [CrossRef]

20. Finnegan, P.; Brumbley, S.; O'Shea, M.; Nevalainen, H.; Bergquist, P. Isolation and Characterization of Genes Encoding Thermoactive and Thermostable Dextranases from Two Thermotolerant Soil Bacteria. Curr. Microbiol. 2004, 49, 327-333. [CrossRef]

21. Gan, W.; Zhang, H.B.; Zhang, Y.; Hu, X. Biosynthesis of oligodextrans with different M-w by synergistic catalysis of dextransucrase and dextranase. Carbohydr. Polym. 2014, 112, 387-395. [CrossRef]

22. Kubo, S.; Kubota, H.; Ohnishi, Y.; Morita, T.; Matsuya, T.; Matsushiro, A. Expression and secretion of an Arthrobacter dextranase in the oral bacterium Streptococcus gordonii. Infect. Immun. 1993, 61, 4375-4381. [PubMed]

23. Koenig, D.; Day, D. Induction of Lipomyces starkeyi Dextranase. Appl. Environ. Microbiol. 1989, 55, $2079-2081$. [PubMed]

24. Larsson, A.; Andersson, R.; Ståhlberg, J.; Kenne, L.; Jones, T. Dextranase from Penicillium minioluteum: Reaction course, crystal structure, and product complex. Structure 2003, 11, 1111-1121. [CrossRef]

25. Kim, D.; Robyt, J.F. Dextransucrase constitutive mutants of Leuconostoc mesenteroides B-1299. Enzyme Microb. Technol. 1995, 17, 1050-1056. [CrossRef]

26. Kim, D.; Day, D.F. A new process for the production of clinical dextran by mixed-culture fermentation of Lipomyces starkeyi and Leuconostoc mesenteroides. Enzyme Microb. Technol. 1994, 16, 844-848. [CrossRef]

27. Zhang, Y.-Q.; Li, R.-H.; Zhang, H.-B.; Wu, M.; Hu, X.-Q. Purification, characterization, and application of a thermostable dextranase from Talaromyces pinophilus. Ind. Microbiol. Biotechnol. 2016, 44, 317-327. [CrossRef]

28. Gulder, T.; Moore, B. Chasing the Treasures of the Sea-Bacterial Marine Natural Products. Curr. Opin. Microbiol. 2009, 12, 252-260. [CrossRef]

29. Kalpana, B.J.; Aarthy, S.; Pandian, S. Antibiofilm Activity of $\alpha$-Amylase from Bacillus subtilis S8-18 Against Biofilm Forming Human Bacterial Pathogens. Appl. Biochem. Biotechnol. 2012, 167, 1778-1794. [CrossRef]

30. Cieśliński, H.; Kur, J.; Białkowska, A.; Baran, I.; Makowski, K.; Turkiewicz, M. Cloning, expression, and purification of a recombinant cold-adapted $\beta$-galactosidase from antarctic bacterium Pseudoalteromonas $\mathrm{sp}$. 22b. Protein Expr. Purif. 2005, 39, 27-34. [CrossRef]

31. Margesin, R.; Schinner, F. Properties of cold-adapted microorganisms and their potential role in biotechnology. J. Biotechnol. 1994, 33, 1-14. [CrossRef]

32. Purushe, S.; Prakash, D.; Nawani, N.N.; Dhakephalkar, P.; Kapadnis, B. Biocatalytic potential of an alkalophilic and thermophilic dextranase as a remedial measure for dextran removal during sugar manufacture. Bioresour. Technol. 2012, 115, 2-7. [CrossRef] [PubMed]

33. Papaleo, E.; Tiberti, M.; Invernizzi, G.; Pasi, M.; Ranzani, V. Molecular Determinants of Enzyme Cold Adaptation: Comparative Structural and Computational Studies of Cold- and Warm-Adapted Enzymes. Curr. Protein Pept. Sci. 2011, 12, 657-683. [CrossRef] [PubMed]

34. Majeed, A.; Grobler, S.; Moola, M. The PH of various tooth whitening products on the south African market. S. Afr. Dent. Assoc. 2011, 66, 278-281.

35. Ren, W.; Cai, R.; Yan, W.; Lyu, M.; Fang, Y.; Wang, S. Purification and Characterization of a Biofilm-Degradable Dextranase from a Marine Bacterium. Mar. Drugs 2018, 16, 51. [CrossRef]

36. PleszczyŃSka, M.; Rogalski, J.; Fiedurek, J. Hydrolysis of dextran by Penicillium notatum dextranase and identification of final digestion products. Mycol. Res. 1997, 101, 69-72. [CrossRef]

37. Shi, M.J.; Du, W.J.; Wang, C.; Chen, G.J.; Du, Z.J. Catenovulum sediminis sp. nov., isolated from coastal sediment. Int. Syst. Evol. Microbiol. 2017, 67, 3894-3898. [CrossRef]

38. Schachtele, C.F.; Staat, R.H.; Harlander, S.K. Dextranases from oral bacteria: Inhibition of water-insoluble glucan production and adherence to smooth surfaces by Streptococcus mutans. Infect. Immun. 1975, 12, 309-317.

39. Arnold, W.; Nguyen, T.B.; Mann, L.C. Purification and characterization of a dextranase from Sporothrix schenckii. Arch. Microbiol. 1998, 170, 91-98. [CrossRef]

40. Zohra, R.R.; Aman, A.; Ansari, A.; Haider, M.S.; Qader, S.A.U. Purification, characterization and end product analysis of dextran degrading endodextranase from Bacillus licheniformis KIBGE-IB25. Biol. Macromol. 2015, 78, 243-248. [CrossRef] 
41. Wynter, C.V.A.; Chang, M.; De Jersey, J.; Patel, B.; Inkerman, P.A.; Hamilton, S. Isolation and characterization of a thermostable dextranase. Enzyme Microb. Technol. 1997, 20, 242-247. [CrossRef]

42. Koenig, D.; Day, D. The purification and characterization of a dextranase from Lipomyces starkeyi. Eur. J.Biochem. 1989, 183, 161-167. [CrossRef] [PubMed]

43. Jiao, Y.L. Characterization of a marine-derived dextranase and its application to the prevention of dental caries. J. Ind. Microbiol. Biotechnol. 2014, 41, 17-26. [CrossRef] [PubMed]

44. Jensen, B.; Olsen, J. Extracellular $\alpha$-Glucosidase with Dextran-Hydrolyzing Activity from the Thermophilic Fungus, Thermomyces lanuginosus. Curr. Microbiol. 1996, 33, 152-155. [CrossRef] [PubMed]

45. Wu, D.T.; Zhang, H.B.; Huang, L.J.; Hu, X.Q. Purification and characterization of extracellular dextranase from a novel producer, Hypocrea lixii F1002, and its use in oligodextran production. Process Biochem. 2011, 46, 1942-1950. [CrossRef]

46. Fukumoto, J.; Tsuji, H.; Tsuru, D. Studies on mold dextranases. I. Penicillium luteum dextranase: Its production and some enzymatic properties. J. Biochem. 1971, 69, 1113-1121. [CrossRef] [PubMed]

47. Shimizu, E.; Unno, T.; Ohba, M.; Okada, G. Purification and Characterization of an Isomaltotriose-producing Endo-dextranase from a Fusarium sp. Biosci. Biotechnol. Biochem. 1998, 62, 117-122. [CrossRef]

48. Lee, J.; Nam, S.; Park, H.; Kim, Y.M.; Kim, N.; Kim, G.; Seo, E.S.; Kang, S.S.; Kim, D. Biochemical Characterization of Dextranase from Arthrobacter oxydans and Its Cloning and Expression in Escherichia coli. Food Sci. Biotechnol. 2010, 19, 757-762. [CrossRef]

49. Zhang, Y.M.; Liu, B.L.; Zheng, X.H.; Huang, X.J.; Li, H.Y.; Zhang, Y.; Zhang, T.T.; Sun, D.Y.; Lin, B.R.; Zhou, G.X. Anandins A and B, Two Rare Steroidal Alkaloids from a Marine Streptomyces anandii H41-59. Mar. Drugs 2017, 15, 355. [CrossRef]

50. Hietala-Lenkkeri, A.; Pienihäkkinen, K.; Hurme, S.; Alanen, P. The caries-preventive effect of xylitol/maltitol and erythritol/maltitol lozenges: Results of a double-blinded, cluster-randomized clinical trial in an area of natural fluoridation. J. Paediatr. Dent. 2011, 22, 180-190. [CrossRef]

51. Arruda, A.O.; Senthamarai Kannan, R.; Inglehart, M.R.; Rezende, C.T.; Sohn, W. Effect of 5\% fluoride varnish application on caries among school children in rural Brazil: A randomized controlled trial. Community Dent. Oral Epidemiol. 2012, 40, 267-276. [CrossRef]

52. Miller, G.L. Use of Dinitrosalicylic Acid Reagent for Detection of Reducing Sugars. Anal. Chem. 1959, 31, 426-428. [CrossRef]

53. Christensen, G.D.; Simpson, W.A.; Younger, J.J.; Baddour, L.M.; Barrett, F.F.; Melton, D.M.; Beachey, E.H. Adherence of coagulase-negative staphylococci to plastic tissue culture plates: A quantitative model for the adherence of staphylococci to medical devices. J. Clin. Microbiol. 1985, 22, 996-1006. [PubMed]

54. Wei, G.X.; Campagna, A.N.; Bobek, L.A. Effect of MUC7 peptides on the growth of bacteria and on Streptococcus mutans biofilm. Antimicrob. Chemother. 2006, 57, 1100-1109. [CrossRef] [PubMed]

55. Tao, R.; Tong, Z.; Lin, Y.; Xue, Y.; Wang, W.; Kuang, R.; Wang, P.; Tian, Y.; Ni, L. Antimicrobial and antibiofilm activity of pleurocidin against cariogenic microorganisms. Peptides 2011, 32, 1748-1754. [CrossRef]

(C) 2019 by the authors. Licensee MDPI, Basel, Switzerland. This article is an open access article distributed under the terms and conditions of the Creative Commons Attribution (CC BY) license (http://creativecommons.org/licenses/by/4.0/). 